\title{
1 Earthquake doublet revealed by multiple pulses in lacustrine
}

\section{2 seismo-turbidites}

3 Katleen Wils ${ }^{1}$, Maxim Deprez ${ }^{2}$, Catherine Kissel ${ }^{3}$, Morgan Vervoort ${ }^{1}$, Maarten Van Daele ${ }^{1}$,

4 Mudrik R. Daryono ${ }^{4}$, Veerle Cnudde ${ }^{2,5}$, Danny H. Natawidjaja ${ }^{4}$ and Marc De Batist ${ }^{1}$

$5{ }^{1}$ Renard Centre of Marine Geology, Department of Geology, Ghent University, Belgium

$6 \quad{ }^{2}$ PProGRess/UGCT, Department of Geology, Ghent University, Belgium

$7 \quad{ }^{3}$ Laboratoire des Sciences du Climat et de l'Environnement, Université Paris-Saclay, France

$8{ }^{4}$ Research Center for Geotechnology, Indonesian Institute of Sciences, Indonesia

$9{ }^{5}$ Environmental Hydrogeology, Department of Earth Sciences, Utrecht University, The

$10 \quad$ Netherlands

11 ABSTRACT

Earthquake doublets have been described in fault systems around the world but have not

13 yet been confidently resolved in paleoseismic records. Our current knowledge is limited to

14 historical occurrences, which prevents uncovering potential patterns or common fault behavior.

15 Identifying prehistorical doublets is thus of crucial importance for adequate seismic hazard

16 assessment and risk mitigation. We develop a new methodology to reveal the sedimentary

17 imprint of earthquake doublets in lacustrine paleoseismic records based on flow direction

18 analysis in multipulsed turbidites, as the delayed arrival of turbidity currents originating from the

19 same source location demonstrates the occurrence of individual triggering mechanisms. As

20 grains tend to align in the presence of a flow, we analyze flow directions by determining the

21 dominant orientation of elongated grains using a combination of grain size, paleomagnetism and

22 high-resolution X-ray computed tomography. This methodology is applied to a turbidite 
deposited by the 2007 earthquakes in West Sumatra $\left(\mathrm{M}_{\mathrm{w}} 6.4\right.$ and 6.3, 2 hours apart $)$ and provides

24 the first unmistakable sedimentary evidence for an earthquake doublet. We argue that this

25 methodology has great potential to analyze multipulsed turbidites in various subaquatic

26 paleoseismic records and can reveal the occurrence of unknown earthquake sequences.

\section{INTRODUCTION}

When two earthquakes with similarly high magnitudes on nearby fault segments occur within a few hours' time, they are considered to form an earthquake doublet (e.g. Lay and

Kanamori, 1980). Although such doublets have been described around the world (e.g. Wong and

31 Bott, 1995; Lin et al., 2008; Daryono et al., 2012), evidence is limited to instrumental archives.

32 The lack of traces of prehistoric earthquake sequences in paleoseismic records has implications

33 for seismic hazard assessments based on those records, as inferred major ruptures could have

34 resulted from separate, consecutive earthquakes. Moreover, the recurrence of earthquake

35 doublets along particular faults might point to common fault behavior and local awareness of

36 such consistency can greatly reduce the risk associated with an imminent second shock.

37 Earthquake doublets thus form a particular challenge for seismic hazard analysis and identifying

38 them in paleoseismic records is of crucial importance.

Turbidite stratigraphy has proven to be a powerful approach for paleoseismic

reconstructions in subaqueous settings (e.g. Goldfinger et al., 2003; Howarth et al., 2012;

41 Moernaut et al., 2014; Wils et al., 2020) and seismo-turbidites have the potential to record

42 closely-timed events (e.g. Van Daele et al., 2015; Migeon et al., 2017). However, deposition of a

43 turbidite and especially its fine-grained cap usually takes longer than a few hours: once the

44 current has ceased, settling of $1 \mu \mathrm{m}$ particles from a $1 \mathrm{~m}$ thick suspension cloud would take

45 about two weeks (Stokes, 1851). Consecutive earthquakes within such timeframes therefore do 
not result in separate turbidites, but in the deposition of a single, amalgamated turbidite that consists of multiple flow pulses, potentially originating from various source areas, deposited on top of each other. Identification of similar source areas in multiple successions of turbidite pulse amalgamation, clearly offset in time, then forms the most compelling argument for the occurrence of an earthquake sequence. To determine turbidite source areas, flow directions can be used, which in sediment cores can be reconstructed by ripples or convolute laminations (e.g. Van Daele et al., 2014). In absence of such sedimentary structures, the orientation and imbrication of individual grains can also reveal paleoflow directions, as has been successfully used for coarse-grained tsunami deposits (e.g. Paris et al., 2010; May et al., 2016).

Here, we combine grain size, paleomagnetic core orientation and high-resolution X-ray computed tomography $(\mu \mathrm{CT})$ to establish sediment micro-fabric in lacustrine turbidites and infer depositional and flow dynamics. As a test case, we study a seismo-turbidite related to the 2007 earthquake doublet in West Sumatra identified in short sediment cores from Lake Singkarak.

\section{SETTING}

Sumatra is the largest island in the Indonesian archipelago, located along the Sunda megathrust where the Indo-Australian plate subducts beneath the Eurasian plate (Fig. 1A). The trench-parallel component of the oblique subduction is partially accommodated by the Sumatran Fault, a large dextral strike-slip fault system (Sieh and Natawidjaja, 2000). Lake Singkarak is located on this fault, occupying a tectonic basin formed by dextral slip on two overstepping segments in the highlands close to Padang, the capital of West Sumatra. These are termed the Sumani and Sianok segments, which consecutively ruptured in $\mathrm{M}_{\mathrm{w}} 6.4$ and 6.3 earthquakes in March 2007 within 2 hours' time (Fig. 1). Both of these earthquakes nucleated in the NW part of the lake, causing local shaking intensities of $\mathrm{VI}-\mathrm{VI} I^{1} / 2$, and propagated in opposite directions 
69 along the respective fault segments (Nakano et al., 2010). The sedimentary imprint of the 2007

70 earthquakes has been identified in short sediment cores retrieved from Lake Singkarak as a

71 widespread turbidite, which in two distal core locations consists of separate coarse-grained

72 subdivisions that could represent the individual earthquakes in the doublet (Wils et al., 2021).

73 METHODS

74 This section provides the essentials of the studied sediment cores and used methods-

75 further elaborated in the Supplemental Material.

76 We analyzed the 2007 turbidite in Lake Singkarak in four cores (Fig. 1B) - two slope-

77 proximal cores for methodological verification (SN17-02B, SN17-06A) and the distal cores with

78 two coarse-grained intervals (SN17-04A, SN17-09A) - by laser diffraction grain-size analysis

79 and report the D10, geometric mean and sorting values (Table S2, Blott and Pye, 2001).

80 U-channel subsamples with a $2 \times 2 \mathrm{~cm}$ cross-section were taken over the full length of

81 each core. They were stepwise demagnetized by alternating fields to reveal the direction of the

82 characteristic remanent magnetization (ChRM; inclination, declination) defined by principal

83 component analysis (Table S4). The ChRM is precisely defined with maximum angular

84 deviations (MAD) mostly below $3^{\circ}$. Because the magnetic moment of minerals deposited by

85 hemipelagic settling is lined up according to the prevailing magnetic field, the core can be

86 geographically oriented in the horizontal plane by aligning the obtained average declination to

87 the magnetic north.

88 The coarse-grained intervals of the 2007 turbidite in each U-channel were $\mu$ CT scanned.

89 A voxel size of $15 \mu \mathrm{m}$ was chosen for all overview scans, visualizing grains with sizes down to

$90 \sim 100 \mu \mathrm{m}$. Region-of-interest (ROI) scans of the U-channel center were obtained using a voxel

91 size of $7 \mu \mathrm{m}$. To digitally identify individual grains, all obtained $\mu \mathrm{CT}$ volumes were processed 
using the same workflow set out in the Avizo software package. This included a series of binary operations and a watershed algorithm, after which the size, elongation and orientation (trend and

94 plunge) of each grain were measured. The orientations of all elongated grains $>100 / 150 \mu \mathrm{m}$

95 (Table S5) were plotted on a stereoplot (Cardozo and Allmendinger, 2013). Several pulses (a, b,

96 c, d), marked by a single flow direction, could be identified within the coarse-grained intervals (1

97 or 2) of the turbidite at each location (e.g. the first turbidite pulse in the second coarse-grained

98 subdivision is referred to as pulse 2a for that core). For each of these pulses, the Bingham axial

99 distribution algorithm (Fisher et al., 1987) was applied to all retained grains to show the principal

100 component (PC1, Table S6) and objectively reveal the main paleocurrent direction. In case the

101 basal plane of a specific pulse was tilted, likely due to core deformation during or after core

102 retrieval (e.g. degassing), orientation parameters were corrected so that they are measured with

103 respect to the actual basal plane rather than a horizontal one.

104 FLOW DIRECTIONS

To infer the orientation of each core, sediments are first categorized as background

106 (steady-state accumulation) or event (turbidites and slumps) deposits following interpretations by

107 Wils et al. (2021). Background deposits show consistent magnetic declinations in each core,

108 illustrating that of the geomagnetic field during deposition (Fig. 2). The majority of event

109 deposits, including the 2007 turbidite, show similar declinations, indicating that their magnetic

110 moment also aligned to the magnetic north. In contrast, the oldest event deposits in SN17-04A

111 and SN17-06A show an abrupt shift in declination that points to reworked (slumped) material. In

112 SN17-02B, a gradual change in declination (and inclination) is observed below the 2007 turbidite

113 and coincides with a significant increase in MAD (up to $14^{\circ}$, Fig. 2). The magnetization in these

114 horizons is thus unstable, leading to an unreliable record of the geomagnetic field that may result 
115 from changes in the magnetic content (e.g. grain-size mixture). These horizons are discarded for 116 calculation of the average declination (Fig. 2).

117 For each pulse identified in the 2007 Singkarak turbidite (Fig. 3), the preferential

118 orientation of all elongated grains (PC1) is translated into paleoflow directions (Fig. 4). While

119 the dominant flow direction can be either parallel or perpendicular to the longest shape axis of 120 elongated grains (Allen, 1982), transverse fabrics are rare in turbidites and flow-parallel long 121 axes are generally assumed (e.g. Sakai et al., 2002; Mulder et al., 2009; Felletti et al., 2016).

122 Furthermore, grains are imbricated along their long axis as can be seen on the stereoplots (Fig. 123 4A-D). The dominant orientation of the long axis in the 2007 turbidite thus indicates the flow 124 direction. Grain imbrication results in an up-current dipping direction of the grain (e.g. Sakai et 125 al., 2002; Felletti et al., 2016) and is used to derive flow sense. This shows that the single coarse126 grained interval in SN17-02B consists of three individual pulses with a distinct origin (Fig. 4).

127 Grain-size data supports this interpretation, showing a new graded sequence in each pulse of 128 which the base is coarser than the top of the previous sequence (Fig. 3). The PC1 of pulse 1a 129 indicates a flow coming from the gradual $\mathrm{N}$ lake slope, followed by pulse $1 \mathrm{~b}$ originating from the 130 steep slopes located NW of the core location. Similarly, the single turbidite pulse in SN17-06A

131 likely originates from the slopes NE of the core location although imbrication in this core cannot 132 be reliably determined due to a non-uniformly dipping basal plane (Fig. 3). The first turbidite 133 pulses in the slope-proximal cores can thus be linked to the lake slopes nearest to the respective 134 core site, indicating that combining paleomagnetic orientation of the cores and our assumptions 135 on grain fabric is a reliable approach to reveal paleoflow directions. 
138 subdivisions, separated by a few cm of fine-grained diatomaceous sediment (Wils et al., 2021).

139 These intervals show limited sorting variability (Fig. 3) and MAD intermediate between those

140 obtained in the coarse-grained sediments below and background sediments (Fig. 2). This

141 suggests gradual deposition from the body of the turbidity current during a waning flow, further

142 supported by their decreasing D10 trend ( $\sim 6$ to $4 \mu \mathrm{m}$, Table S2). A delay is thus present between

143 deposition of both coarse-grained intervals, which is shorter than the time required for all fine-

144 grained material to settle (turbidite cap, $<4 \mu \mathrm{m}$ ). This would be in the order of hours to days,

145 depending on the thickness of the suspension cloud (Stokes, 1851). A similar sedimentation

146 pattern has been observed for diatom-rich turbidity currents in lakes in Chile and Kenya (Van

147 Daele et al., 2017), where synchronous triggering on multiple basin slopes at up to several km

148 difference in distance to the core site resulted in an arrival delay in the order of minutes to hours

149 for flow velocities of 0.2 to $1 \mathrm{~m} / \mathrm{s}$, which is the most likely flow velocity range for the deposits

150 described here (cf. Sumner et al., 2009). In our data, an arrival delay due to destabilization of

151 other lake slopes can be ruled out as the successive sandy beds in both cores show similar flow

152 direction (Fig. 4; mostly originating from the NE slopes in SN17-04A and W slopes in SN17-

153 09A). The similar color and radiodensity signature of pulse 1d and 2c in SN17-09A additionally

154 supports their common origin (Fig. 3). As deposition of coarse-grained material occurs at higher

155 flow velocities (Sumner et al., 2009) and the upper of both coarse-grained subdivisions is also

156 coarsest in both cores, the second turbidity current must have had a higher flow velocity. This

157 further challenges the possibility for a delayed turbidity current arrival in absence of a second

158 external trigger mechanism. The combination of flow direction and grain-size analysis thus

159 confirms that the 2007 turbidite at both distal core sites forms an amalgamated turbidite with a 
160 stacked appearance triggered by both earthquakes in the doublet, of which the 2 hour separation

161 is in range with the estimated depositional delays.

162 Our study shows that lacustrine seismo-turbidites can reveal past earthquake doublets,

163 even if individual events are separated by no more than a few hours. Identification of separate

164 turbidity currents originating from the same source area in a series of amalgamated turbidity

165 currents is the most compelling argument for successive earthquakes. Nevertheless, the

166 combination of paleoflow analysis with grain-size data is crucial to rule out potential

167 confounding processes such as seiching or slope failures in absence of a second external trigger.

168 As such external trigger could also be a local event (e.g. aftershock), our methodology is

169 especially suitable in locations where overlapping fault segments occur and should ideally be

170 combined with other paleoseismic studies along these fault segments. This opens up prospects

171 for recognizing prehistorical earthquake sequences in subaquatic settings around the world,

172 which would significantly advance seismic hazard assessments.

173 ACKNOWLEDGMENTS

174 K.W. acknowledges the Special Research Fund (BOF) of Ghent University. Fieldwork 175 was funded by the Research Foundation Flanders (FWO, G042812N) and carried out with an 176 Indonesian FRP permit (7B/TKPIPA/E5/Dit.KI/VII/2017). The authors thank all fieldwork 177 participants and S.Y. Cahyarini and the Indonesian Customs for sediment core shipment. The 178 authors are grateful for the constructive comments of M. Strasser, J. Howarth and an anonymous 179 reviewer on an earlier version of this manuscript.

180 REFERENCES CITED 
181 Allen, J. R. L., 1982, Orientation of particles during sedimentation: Shape-fabrics, in Allen, J. R. L., ed., Sedimentary Structures, Their Character and Physical Basis, Volume I: The Netherlands, Elsevier, p. 179-235.

Blott, S. J., and Pye, K., 2001, GRADISTAT: a grain size distribution and statistics package for the analysis of unconsolidated sediments: Earth Surface Processes and Landforms, v. 26, p. 1237-1248, https://doi.org/10.1002/esp.261.

Cardozo, N., and Allmendinger, R. W., 2013, Spherical projections with OSXStereonet: Computers \& Geosciences, v. 51, p. 193-205, https://doi.org/10.1016/j.cageo.2012.07.021.

190 Daryono, M. R., Natawidjaja, D. H., and Sieh, K., 2012, Twin-surface ruptures of the March 2007 M>6 earthquake doublet on the Sumatran Fault: Bulletin of the Seismological

Felletti, F., Dall'Olio, E., and Muttoni, G., 2016, Determining flow directions in turbidites: An integrated sedimentological and magnetic fabric study of the Miocene Marnoso Arenacea Formation (northern Apennines, Italy): Sedimentary Geology, v. 335, p. 197-215, https://doi.org/10.1016/j.sedgeo.2016.02.009.

Fisher, N. I., Lewis, T., and Embleton, B. J. J., 1987, Statistical Analysis of Spherical Data: Cambridge, Cambridge University Press, 329 p.

199 Goldfinger, C., Nelson, C. H., and Johnson, J. E., 2003, Holocene earthquake records from the $200 \quad$ Cascadia subduction zone and northern San Andreas Fault based on precise dating of 201 offshore turbidites: Annual Review of Earth and Planetary Sciences, v. 31, p. 555-577, https://doi.org/10.1146/annurev.earth.31.100901.141246. 
Howarth, J. D., Fitzsimons, S. J., Norris, R. J., and Jacobsen, G. E., 2012, Lake sediments record cycles of sediment flux driven by large earthquakes on the Alpine fault, New Zealand: Geology, v. 40, p. 1091-1094, https://doi.org/10.1130/g33486.1.

Kamb, W. B., 1959, Ice petrofabric observations from Blue Glacier, Washington, in relation to theory and experiment: Journal of Geophysical Research, v. 64, p. 1891-1909, https://doi.org/10.1029/JZ064i011p01891.

Lay, T., and Kanamori, H., 1980, Earthquake doublets in the Solomon Islands: Physics of the Earth and Planetary Interiors, v. 21, p. 283-304, https://doi.org/10.1016/00319201(80)90134-X.

Lin, C.-H., Yeh, Y.-H., Ando, M., Chen, K.-J., Chang, T.-M., and Pu, H.-C., 2008, Earthquake doublet sequences: Evidence of static triggering in the strong convergent zones of Taiwan: Terrestrial, Atmospheric and Oceanic Sciences, v. 19, p. 589-594, https://doi.org/10.3319/tao.2008.19.6.589(pt).

May, S. M., Falvard, S., Norpoth, M., Pint, A., Brill, D., Engel, M., Scheffers, A., Dierick, M., Paris, R., Squire, P., and Brückner, H., 2016, A mid-Holocene candidate tsunami deposit from the NW Cape (Western Australia): Sedimentary Geology, v. 332, p. 40-50, https://doi.org/10.1016/j.sedgeo.2015.11.010.

Migeon, S., Garibaldi, C., Ratzov, G., Schmidt, S., Collot, J. Y., Zaragosi, S., and Texier, L., 2017, Earthquake-triggered deposits in the subduction trench of the north Ecuador/south Colombia margin and their implication for paleoseismology: Marine Geology, v. 384, p. 47-62, https://doi.org/10.1016/j.margeo.2016.09.008.

Moernaut, J., Van Daele, M., Heirman, K., Fontijn, K., Strasser, M., Pino, M., Urrutia, R., and De Batist, M., 2014, Lacustrine turbidites as a tool for quantitative earthquake 
reconstruction: New evidence for a variable rupture mode in south central Chile: Journal of Geophysical Research: Solid Earth, v. 119, p. 1607-1633, https://doi.org/10.1002/2013jb010738.

Mulder, T., Zaragosi, S., Razin, P., Grelaud, C., Lanfumey, V., and Bavoil, F., 2009, A new conceptual model for the deposition process of homogenite: Application to a cretaceous megaturbidite of the western Pyrenees (Basque region, SW France): Sedimentary Geology, v. 222, p. 263-273, https://doi.org/10.1016/j.sedgeo.2009.09.013.

Nakano, M., Kumagai, H., Toda, S., Ando, R., Yamashina, T., Inoue, H., and Sunarjo, 2010, Source model of an earthquake doublet that occurred in a pull-apart basin along the Sumatran fault, Indonesia: Geophysical Journal International, v. 181, p. 141-153, https://doi.org/10.1111/j.1365-246X.2010.04511.x.

Paris, R., Fournier, J., Poizot, E., Etienne, S., Morin, J., Lavigne, F., and Wassmer, P., 2010, Boulder and fine sediment transport and deposition by the 2004 tsunami in Lhok Nga (western Banda Aceh, Sumatra, Indonesia): A coupled offshore-onshore model: Marine Geology, v. 268, p. 43-54, https://doi.org/10.1016/j.margeo.2009.10.011.

Sakai, T., Yokokawa, M., Kubo, Y. S., Endo, N., and Masuda, F., 2002, Grain fabric of experimental gravity flow deposits: Sedimentary Geology, v. 154, p. 1-10, https://doi.org/10.1016/s0037-0738(02)00106-9.

Sieh, K., and Natawidjaja, D., 2000, Neotectonics of the Sumatran Fault, Indonesia: Journal of Geophysical Research: Solid Earth, v. 105, p. 28295-28326, https://doi.org/10.1029/2000jb900120.

Stokes, G. G., 1851, On the effect of the internal friction of fluids on the motion of pendulums: Transactions of the Cambridge Philosophical Society, v. 9, p. 8-106. 
Sumner, E. J., Talling, P. J., and Amy, L. A., 2009, Deposits of flows transitional between turbidity current and debris flow: Geology, v. 37, p. 991-994, https://doi.org/10.1130/g30059a.1.

252

253

254

255

256

257

258

259

260

261

262

263

264

265

266

267

268

269

270

271

Van Daele, M., Cnudde, V., Duyck, P., Pino, M., Urrutia, R., De Batist, M., and Trofimovs, J., 2014, Multidirectional, synchronously-triggered seismo-turbidites and debrites revealed by X-ray computed tomography (CT): Sedimentology, v. 61, p. 861-880, https://doi.org/10.1111/sed.12070.

Van Daele, M., Meyer, I., Moernaut, J., De Decker, S., Verschuren, D., and De Batist, M., 2017, A revised classification and terminology for stacked and amalgamated turbidites in environments dominated by (hemi)pelagic sedimentation: Sedimentary Geology, v. 357, p. 72-82, https://doi.org/10.1016/j.sedgeo.2017.06.007.

Van Daele, M., Moernaut, J., Doom, L., Boes, E., Fontijn, K., Heirman, K., Vandoorne, W., Hebbeln, D., Pino, M., Urrutia, R., Brümmer, R., De Batist, M., and Trofimovs, J., 2015, A comparison of the sedimentary records of the 1960 and 2010 great Chilean earthquakes in 17 lakes: Implications for quantitative lacustrine palaeoseismology: Sedimentology, v. 62, p. 1466-1496, https://doi.org/10.1111/sed.12193.

Wils, K., Daryono, M. R., Praet, N., Santoso, A. B., Dianto, A., Schmidt, S., Vervoort, M., Huang, J. S., Kusmanto, E., Suandhi, P. A., Natawidjaja, D. H., and De Batist, M., 2021, The sediments of Lake Singkarak and Lake Maninjau in West Sumatra reveal their earthquake, volcanic and rainfall history: Sedimentary Geology, v. 416, 105863, https://doi.org/10.1016/j.sedgeo.2021.105863.

Wils, K., Van Daele, M., Kissel, C., Moernaut, J., Schmidt, S., Siani, G., and Lastras, G., 2020, Seismo-turbidites in Aysén Fjord (southern Chile) reveal a complex pattern of rupture 
modes along the 1960 megathrust earthquake segment: Journal of Geophysical Research: Solid Earth, v. 125, e2020JB019405, https://doi.org/10.1029/2020JB019405.

274 Wong, I. G., and Bott, J. D. J., 1995, A new look back at the 1969 Santa Rosa, California, 275 earthquakes: Bulletin of the Seismological Society of America, v. 85, p. 334-341.

\section{FIGURE CAPTIONS}

Fig. 1. A: Setting of Lake Singkarak, West Sumatra, located on the Sumani and Sianok segments of the Sumatran Fault and along the Sunda megathrust. The lake is located close to Padang, the region's capital. B: Bathymetry map of the lake (20 m contours) showing the 281 location of the four studied cores (SN17-02B, SN17-04A, SN17-06A and SN17-09A) and the 282 most important rivers. Fault trace of both segments involved in the 2007 earthquake doublet after 283 Sieh and Natawidjaja (2000), rupture propagation (colored arrows), epicenter location and focal 284 mechanisms after Nakano et al. (2010). Modified from Wils et al. (2021).

Fig. 2. Declination (dark blue) and maximum angular deviations (MAD, purple) derived

286 from paleomagnetic analysis for the four cores in Lake Singkarak with interpretation of

287 background (gray) and event sedimentation (green) following Wils et al. (2021). The 2007 288 seismo-turbidite and its coarse-grained intervals are indicated in dark green (see Fig. 3). The 289 average declination (dashed line) indicates the north direction in the ChRM reference frame of 290 each U-channel, calculated by discarding event deposits with unreliable declination values (white 291 shading). The lower left shows a schematic representation of a U-channel with respect to the 292 sediment core. On the lower right, schematic U-channel bottom views show the declination 293 direction for each core. 
Fig. 3. $\mu \mathrm{CT}$ scans and pictures of the 2007 seismo-turbidite in Lake Singkarak (see Fig.

295 2) with indication of grain-size parameters (mean, light blue and sorting, gray). White rectangles

296 mark the $\mu \mathrm{CT}$-scanned sections. Turbidite pulses are indicated by colored rectangles and

297 alphabetically named per coarse-grained interval in order of deposition. For SN17-02B, SN17-

298 04A and SN17-06A, overview scans were used (resolution 15x15x15 $\mu \mathrm{m}$ ) while for the finer-

299 grained SN17-09A, ROI scans $(7 \times 7 \times 7 \mu \mathrm{m})$ were required to achieve adequate grain

300 segmentation.

301 Fig. 4. A-D: Lower-hemisphere stereoplots showing plunge and trend of strongly

302 elongated grains derived from $\mu \mathrm{CT}$ data analysis and measured with respect to the basal plane

303 for each pulse in the 2007 seismo-turbidite for the four cores in Lake Singkarak (see Fig. 3).

304 Each stereoplot, in the $\mu \mathrm{CT}$ reference frame of the U-channel, is rotated so that geographic north

305 is oriented to the figure top (see U-channel bottom view insets and compare to Fig. 2).

306 Considered grain sizes and total amount of grains (n) are indicated at the bottom-left of each

307 plot. Contour lines (Kamb, 1959) and Bingham axial distribution analysis (Fisher et al., 1987)

308 show the main orientation in each dataset (principal component PC1, red square) and indicate the

309 flow direction (colored arrows). Flow sense is derived by considering the dominant imbrication

310 as up-current dipping. E: Geographical context of the resulting flow directions at each of the core

311 sites (see Fig. 1B). The dashed arrow for SN17-06A indicates an unlikely flow direction that

312 cannot be ruled out with the available data. 


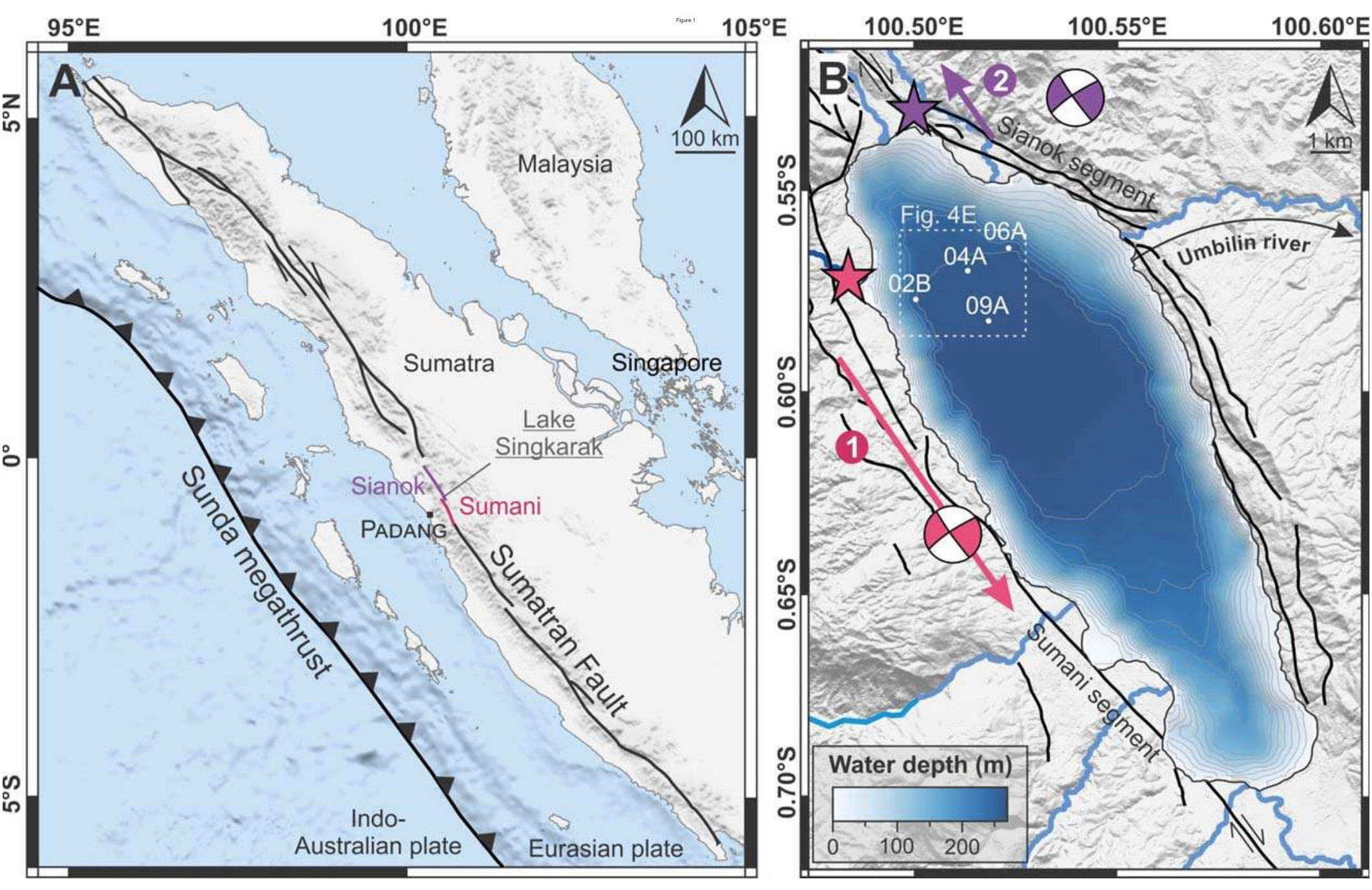




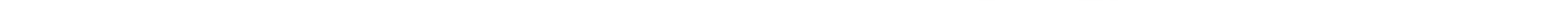




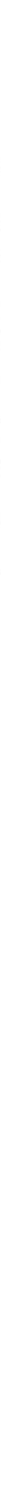




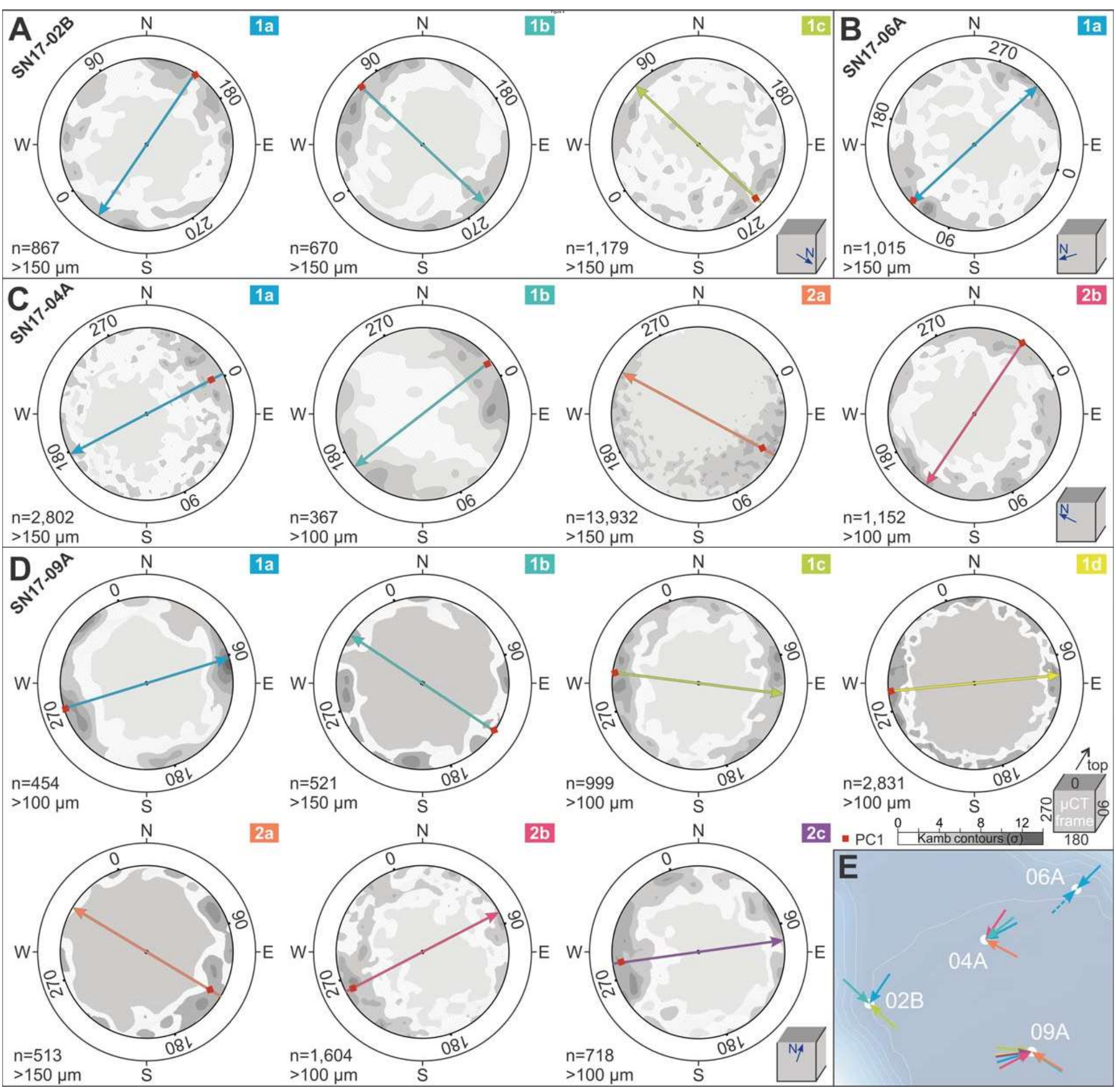

